\title{
Potential Cosmeceutical Applications and Evaluation of Human Skin Irritation of Tagetes erecta L. Flower Extract
}

\author{
Catheleeya Mekjaruskul ${ }^{1, *}$, Supakanya Kumkarnjana', Niramai Fangkrathok ${ }^{2}$, Worapol Kengkittipat ${ }^{1}$, \\ Nuttawut Sirichat ${ }^{1}$
}

\section{Catheleeya Mekjaruskul1,*, Supakanya Kumkarnjana', Niramai Fangkrathok ${ }^{2}$, Worapol Kengkittipat ${ }^{1}$, Nuttawut Sirichat ${ }^{1}$}

\section{'Faculty of Pharmacy, Mahasarakham University, Kantharawichai, Maha Sarakham, THAILAND. \\ ${ }^{2}$ Faculty of Agricultural Technology, Burapha University, Sakaeo Campus, Watthana Nakhon, Sa Kaeo, THAILAND. \\ Correspondence}

Asst.Prof. Dr. (Assistant Professor, Ph.D.) Catheleeya Mekjaruskul

Faculty of Pharmacy, Mahasarakham University, Kantharawichai, Maha Sarakham-44150, THAILAND. Phone no: +668-1768-5684 Email id: catheleeya.m@msu.ac.th

\section{History}

- Submission Date: 14-07-2021;

- Review completed: 27-08-2021

- Accepted Date: 18-09-2021

\section{DOI : 10.5530/pres.13.4.12}

Article Available online

http://www.phcogres.com

\section{Copyright}

(C) 2021 Phcog.Net. This is an openaccess article distributed under the terms of the Creative Commons Attribution 4.0 International license.

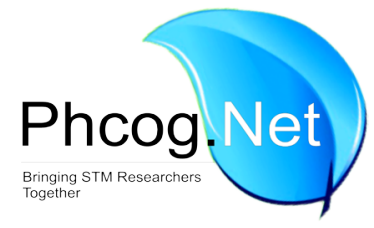

\begin{abstract}
Background: Tagetes erecta L. has been traditionally used for treatment of skin diseases. Objectives: This study aimed to evaluate in vitro skin anti-aging, antioxidant, antibacterial activities, and human skin irritation of T. erecta flower extract for development as a cosmeceutical skin product using aqueous, $50 \%$, and $95 \%$ ethanolic extracts of $T$. erecta flower. Methods: Total phenolic content was defined. Quantitative analysis of syringic acid was determined by using HPLC. Antioxidant activities were performed by measurement of 2,2-diphenyl 1-pichylhydazyl free radical scavenger. Anti-aging assays were monitored inhibitory effects on tyrosinase, elastase, hyaluronidase, and collagenase activities. Antibacterial effects against Staphylococcus aureus and Staphylococcus epidermidis was also investigated. The extract was formulated as a lotion and its stability study was evaluated and human skin irritation tests were performed. Results: The 95\% ethanolic extract had significantly higher total phenolic content and syringic acid content than the other extracts. The 95\% ethanolic extract also had stronger inhibitory activities on DPPH scavenging and against tyrosinase, elastase and hyaluronidase enzyme activities than those of $50 \%$ ethanolic or water extracts. The $95 \%$ ethanolic extracts showed a better antibacterial activity against $S$. aureus and S. epidermidis. The developed lotion containing $1 \%$ of T. erecta extract using $95 \%$ ethanol was stable. Moreover, skin irritation was not observed in healthy volunteers after applying the T. erecta lotion. Conclusion: This study indicates that T. erecta flower extracts, especially a $95 \%$ ethanolic extract, are potential sources for development of cosmeceutical skin products against enzymes/reactions responsible for skin aging and bacterial skin infection.

Key words: Asteraceae, Tagetes erecta L., Marigold, Anti-aging, Skin irritation.
\end{abstract}

\section{INTRODUCTION}

Tagetes erecta L., commonly known as marigold or "Dow Ruang" in Thai, belongs to the Asteraceae family. It is generally a wild growing plant, but it is also cultivated for ceremonial, decorative, and herbalmedicinal remedies. It is rich of phenolic compounds. ${ }^{[1]}$ Phytochemical studies have shown that thiophenes, flavonoids, carotenoids, triterpinoids, methyl-3,5-dihydroxy-4-methoxy benzoate, and ethyl gallate are present in T. erecta flowers. ${ }^{[2]}$ Syringic acid and $\beta$-amyrin, which were isolated from $T$. erecta flowers, were the bioactive compounds due to they possess inhibitory activities on hyaluronidase, elastase, and collagenase enzymes. ${ }^{[3]}$

Traditionally, this plant has been claimed to be effective for treatment of skin diseases including wounds, burns, carbuncles, eczema, as well as piles, muscular pain and muscle relaxant, rheumatic pain, respiratory diseases, and kidney troubles. ${ }^{[4-6]}$ The flowers of $T$. erecta have been reported to contain various pharmacological activities such as antioxidant, ${ }^{[1,7,8]}$ antibacterial (Streptococcus mutans, Pseudomonas aeroginosa), ${ }^{[7]}$ anxiolytic and sedative-like activities, ${ }^{[9]}$ and treatment of ulcerative colitis. ${ }^{[8]}$ Considering cosmeceutical application, methanolic extract of T. erecta flowers was reported to exhibit anti-elastase, anti-hyaluronidase, and anti-collagenase activities. ${ }^{[3]}$ Ethyl acetate extract of $T$. erecta flower showed antioxidation or anti-tyrosinase effects. ${ }^{[10]}$ Vallisuta et al. also reported that ethyl acetate extract of T. erecta flower possessed a strong elastase inhibitory activity and its ethanolic extract showed anti-tyrosinase effect. ${ }^{[11]}$ Creams containing 30\% nanostructured lipid carriers of T. erecta flower ethyl acetate extract reduced skin wrinkles compared with untreated and cream base in healthy volunteers after application for 8 weeks. ${ }^{[12]}$ These reports showed that T. erecta flower extract had the potential to be used as cosmeceutical products.

Nowadays, cosmeceutical products for prevention and treatment for skin aging have received
Cite this article: Mekjaruskul C, Kumkarnjana S, Fangkrathok N, Kengkittipat W, Sirichat N Potential Cosmeceutical Applications and Evaluation of Human Skin Irritation of Tagetes erecta L. Flower Extract. Pharmacog Res. 2021;13(4):199-207. 
increasing interest. Mechanisms underlying the development of skin aging involve many enzymes and other factors. Elastase is an enzyme that is responsible primarily for cleaving elastin in skin causing loss of skin elasticity and resilience. Hyaluronidase is an enzyme that is capable of cleaving hyaluronic acid or hyaluronan which is mucopolysaccharide providing skin hydration and skin elasticity. Collagen in skin acts as supporter of skin structure providing skin firming and is responsible for the tensile strength of the skin. Collagen can be broken down by collagenase enzyme. ${ }^{[13]}$ Increasing degradation of elastin, hyaluronic acid, and collagen are significant in the aging process. Thereby, the inhibition of these three enzymes activities can prevent loss of skin elasticity, reduce skin wrinkles, delay skin aging, and improve skin hydration. Additionally, skin aging can be caused by UV exposure induced oxidation reactions. The continuous exposure of UV radiation can stimulate physical changes in skin through the formation of lipid peroxides and reactive oxygen species leading to loss of elasticity, skin wrinkles, uneven pigmentation, brown spots, and melanoma. ${ }^{[13]}$ Thus, maintaining antioxidant homeostasis is also a proper strategy to prevent skin aging by quenching reactive oxygen species produced during UV radiation exposure. Additionally, melasma is also a problem of skin aging caused by an increase of melanin resulting from induction of tyrosinase. Tyrosinase is known as an enzyme that plays a role in the melanin synthesis in melanocytes. The activation of tyrosinase enzymes, which mostly results from UV radiation exposure, results in hyperpigmentation in epidermis and dermis. The accumulation of excessive pigmentation results in melasma, age spots, and freckles associated with age. ${ }^{[14]}$ Thus, tyrosinase inhibitors are useful cosmeceutical ingredients as they reduce uneven pigmentation, brown spots, and melanoma on skin.

Besides, cosmeceutical products have been also utilized for prevention or treatments of bacterial infections that can cause blister or acne. Acne is the most common disorder of human skin associated with microbial infection. Propionibacterium acnes, Staphylococcus epidermidis, Staphylococcus aureus, and Candida albicans are commonly found to cause acne. ${ }^{[15-17]}$ However, antimicrobial agents which are mostly synthetic compounds, can cause drug resistance, adverse effects, and skin allergy/ irritation. ${ }^{[16]}$ There is increasing interest in antimicrobial products for acne treatment from natural sources in order to decrease the incidence of drug resistance.

Aforementioned, the previous studies showed that aqueous and ethanolic extracts of T. erecta flowers possessed a good antioxidant activity. Antielastase, anti-hyaluronidase, and anti-collagenase activities were also found in methanol extract of T. erecta flowers. Moreover, ethyl acetate extract of $T$. erecta flowers possessed anti-elastase activity. These results suggest that $T$. erecta flower has a potential to be developed as a cosmeceutical product for skin care products. Nevertheless, the residual methanol and ethyl acetate may remain in the products which are able to penetrate into skin and can cause skin toxicity and skin irritation. ${ }^{[18,19]}$ The biocompatible and low toxicity solvents should be utilized for the plant extraction. In general, the use of different solvents for plant extraction may provide different chemical constitutes and demonstrate the different biological effects. To the best of our knowledge, biological effects and benefits on the skin of T. erecta flowers extracted with water or ethanol have been rarely investigated. Therefore, the aim of this study was to investigate the skin efficacy including antioxidant, anti-tyrosinase, anti-elastase, anti-hyaluronidase, anti-collagenase, and antibacterial activity against $S$. aureus and $S$. epidermidis of T. erecta flower extracts by using biocompatible and the low toxicity solvents including water and ethanol for the plant extraction. Additionally, a skin product prototype was then developed in order to test the stability of T. erecta flower extract when formulated as a skin care product and to evaluate skin irritation in healthy volunteers after applying the product prototype.

\section{MATERIALS AND METHODS}

\section{Chemicals}

Gallic acid, collagenase activity colorimetric assay kits, elastase from porcine pancreas, $\mathrm{N}$-succinyl-(Ala)-3-nitroaniline (SANA), N-[3-(2-furyl) acryIoyl]-Leu-Gly-Pro-Ala (FALGPA), hyaluronidase from bovine testes, 3',4'-dihydroxy-l-phenylalanine (L-DOPA), tyrosinase from lyophilized mushroom powder, syringic acid, and epigallocatechin were purchased from Sigma-Aldrich', USA. Hyaluronic acid sodium salt from rooster comb from Sigma-Aldrich (China), ascorbic acid and 2,2-diphenyl-1-picrylhydrazy (DPPH) from Sigma-Aldrich (Germany), folin ciocalteu reagents from Loba (India), and oleanolic acid from Chengdu Biopurify Phytochemicals (China) were used. Mueller Hinton broth (MHB), Mueller Hinton agar (MHA), and soyabean casein digest agar were procured from Himedia, India. Clindamycin was obtained from Oxoid, UK. Bovine serum albumin was purchased from Acros Organics, USA. All chemicals for formulation were cosmeceutical grade and purchased from Chemipan Corporation Co., Ltd (Thailand). Other solvents and reagents used were of analytical grade.

\section{Preparation of plant extracts}

T. erecta flowers, 60 days old at flowering stage, were collected from an organic plantation in Nakhonratchasima province, Thailand. A voucher specimen (No. TE2561) has been deposited at the Faculty of Pharmacy, Mahasarakham University, Thailand. The flowers were washed twice with DI water. The yellow parts of the flowers were then separated, and small pieces were dried at $45^{\circ} \mathrm{C}$ in hot air oven for $24 \mathrm{~h}$. The dried samples were ground into fine powder using a herbal grinder. For preparation of aqueous extract, the dried powder was added to hot water at a controlled temperature of $70-80^{\circ} \mathrm{C}$ and allowed to infuse for $1 \mathrm{~h}$, filtered through filter paper (Whatman Number 1) and the filtrate retained as aqueous extract. Afterwards, the filtrates were lyophilized to provide the aqueous extract. For preparation of $50 \%$ and $95 \%$ ethanolic extracts, a maceration technique was employed. The dried powder of $T$. erecta flowers was macerated with $50 \%$ or $95 \%$ ethanol for 5 consecutively days with stirring 3 times a day. After filtration, the liquid extract was concentrated using a rotary evaporator and then the concentrated solution was dried by using lyophilizer. Yields (\%) were calculated by dividing the weight of obtained extract by the dry weight of T. erecta powder. The extracts were kept at $-20^{\circ} \mathrm{C}$ until used.

\section{Determination of total phenolic contents}

The Folin-Ciocalteu colorimetric method was used to determine total phenolic contents in the three extracts as described previously. ${ }^{[20]}$ Briefly, aqueous extract was dissolved in water while $50 \%$ and $95 \%$ ethanolic extracts were dissolved in ethanol to make $0.1-1 \mathrm{mg} / \mathrm{mL}$ solutions. The mixture containing the extract or gallic acid $(20 \mu \mathrm{L}), 10 \%$ folin-ciocalteu reagent $(100 \mu \mathrm{L})$, and $7.5 \% \mathrm{Na}_{2} \mathrm{CO}_{3}(80 \mu \mathrm{L})$, were mixed in 96-well plate and kept in darkness for $2 \mathrm{~h}$. Afterwards, the absorbance was recorded at $765 \mathrm{~nm}$ in UV-microplate reader (Spectro StarNano, Germany). Total phenolic content was calculated based on the amount of gallic acid equivalent ( $\mu \mathrm{g}$ GAE/mg extract). The equivalences were read from the straight line generated by linear regression of absorbances and concentrations of gallic acid.

\section{Quantitative analysis of syringic acid by HPLC}

Determination of syringic acid in the extracts was performed by using HPLC following the previous published article with minor modification. ${ }^{[3]}$ HPLC Shimadzu SCL-10AVP (Japan) coupled with DAD detector was employed. A $\mathrm{C}_{18}$ column $(250 \times 4.6 \mathrm{~mm}, 5 \mu \mathrm{m})$ from Inversion GL science (Japan) was used. Methanol (20\%) and $1.25 \%$ acetic acid in water (80\%) were mobile phases. Flow rate was set at $1 \mathrm{~mL} / \mathrm{min}$. The extracts were 
dissolved in the mixture of mobile phases. Syringic acid in the extracts was detected at a wavelength of $280 \mathrm{~nm}$ at retention time of $31 \mathrm{~min}$.

\section{Antioxidant activity}

DPPH assay was employed according to the previous published article. ${ }^{[21]}$ Aqueous extract and the ethanolic extracts solutions in various concentrations were prepared in DI water and ethanol, respectively. Ascorbic acid was used as a positive control by dissolving in DI water. The extract or ascorbic acid solution $(20 \mu \mathrm{L})$ was mixed with $0.08 \mathrm{mM}$ DPPH solution in ethanol $(80 \mu \mathrm{L})$ in a 96 -well plate. The reaction was allowed to take place at room temperature $\left(25-30^{\circ} \mathrm{C}\right)$ for $15 \mathrm{~min}$ and then the absorbance of the mixture was measured at $517 \mathrm{~nm}$ using a UV-Vis microplate reader (Spectro StarNano, Germany). All determinations were performed in triplicate. The percentage of inhibition in each concentration was calculated according to the following formula:

The percentage of inhibition $=[($ Absorbance of the DPPH solution Absorbance of the mixture of sample and DPPH solution) / Absorbance of the $\mathrm{DPPH}$ solution] $\times 100$

Then, half maximal inhibitory concentration or 50\% inhibitory concentration $\left(\mathrm{IC}_{50}\right)$ was obtained from the linear regression of the percentage of inhibition against sample concentration.

\section{Evaluation of biological activities of T. erecta flower extracts}

\section{Anti-tyrosinase activity}

Anti-tyrosinase activity was investigated by the dopachrome method as described previously using L-DOPA as a substrate and mushroom tyrosinase as an enzyme. ${ }^{[22]}$ Kojic acid was selected as a positive control. Different concentrations of aqueous extract and ethanolic extracts solutions were prepared in DI water and methanol, respectively. Tyrosinase enzyme solution was prepared in phosphate buffer solution (PBS) $\mathrm{pH}$ 6.8 at the concentration of $0.16 \mathrm{mg} / \mathrm{mL}$. L-DOPA was dissolved in PBS pH 6.8 to make $0.85 \mu \mathrm{M} / \mathrm{mL}$ solution. Then, tyrosinase enzyme solution $(20 \mu \mathrm{L})$ was mixed with PBS pH $6.8(140 \mu \mathrm{L})$ and the extract or positive control solution $(40 \mu \mathrm{L})$ in a 96 -well plate. After incubation at room temperature $\left(25-30^{\circ} \mathrm{C}\right)$ for $10 \mathrm{~min}, \mathrm{~L}-\mathrm{DOPA}$ solution $(20 \mu \mathrm{L})$ was added to the mixture. The absorbance of the mixture was read after incubation for $20 \mathrm{~min}$ in room temperature $\left(25-30^{\circ} \mathrm{C}\right)$ using UV-Vis microplate reader (Spectro StarNano, Germany) at $492 \mathrm{~nm}$. The $\mathrm{IC}_{50}$ value was further obtained from the linear regression between the percent inhibition and concentration. The percentage of tyrosinase inhibition was calculated using the following formula:

$$
\% \text { Inhibition }=[(\mathrm{A}-\mathrm{B})-(\mathrm{C}-\mathrm{D}) \times 100] /[(\mathrm{A}-\mathrm{B})]
$$

Where A: absorbance of the mixture of tyrosinase enzyme, PBS $\mathrm{pH}$ 6.8, L-DOPA, and methanol

B: absorbance of the mixture of PBS $\mathrm{pH} 6.8$, L-DOPA, and methanol

$\mathrm{C}$ : absorbance of the mixture of tyrosinase enzyme, PBS $\mathrm{pH}$ 6.8, L-DOPA, and extract/positive control

D: absorbance of the mixture of PBS pH 6.8, L-DOPA, and extract/positive control

\section{Anti-elastase activity}

The assay employed was based on methods from previous literature that monitor the release of p-nitroanilide, product of the enzyme reaction. ${ }^{[23]}$ SANA, which is a substrate, was dissolved in $0.1 \mathrm{~mol} / \mathrm{L}$ Tris- $\mathrm{HCl}$ buffer solution $\mathrm{pH} 8.0$ to make the solution at the concentration of $1 \mathrm{mmol} / \mathrm{L}$. Elastase enzyme solution was prepared to make a $0.03 \mathrm{U} / \mathrm{mL}$ solution in $0.1 \mathrm{~mol} / \mathrm{L}$ Tris- $\mathrm{HCl}$ buffer solution $\mathrm{pH}$ 8.0. Tris- $\mathrm{HCl}$ buffer solution $\mathrm{pH} 8.0(0.1 \mathrm{~mol} / \mathrm{L})$ and methanol were used to dissolve the aqueous and ethanolic extracts, respectively. Oleanolic acid, a positive control, was dissolved in methanol. The extract solution or oleanolic solution $(20 \mu \mathrm{L})$ in various concentrations was preincubated with elastase enzyme $(40 \mu \mathrm{L})$ in a UV transparent 96 -well plate at room temperature $\left(25-30^{\circ} \mathrm{C}\right)$ for $10 \mathrm{~min}$. Afterwards, SANA solution $(200 \mu \mathrm{L})$ was added to the mixture. After incubation at room temperature $\left(25-30^{\circ} \mathrm{C}\right)$ for $60 \mathrm{~min}$, the absorbance of sample was measured at $410 \mathrm{~nm}$ using a UV-Vis microplate reader (Spectro'StarNano, Germany). The following formula was employed for calculation:

$$
\% \text { Inhibition }=[(\mathrm{A}-(\mathrm{B}-\mathrm{C})) \times 100] / \mathrm{A}
$$

Where A: absorbance of mixture of SANA solution, elastase enzyme solution, and $0.1 \mathrm{~mol} / \mathrm{L}$ Tris- $\mathrm{HCl}$ buffer $\mathrm{pH}$ solution 8.0

B: absorbance of mixture of extract/positive control solution, SANA solution, and elastase enzyme solution

C: absorbance of mixture of extract/positive control solution, SANA solution, and $0.1 \mathrm{~mol} / \mathrm{L}$ Tris- $\mathrm{HCl}$ buffer $\mathrm{pH} 8.0$ solution

The \%inhibition and concentration were plotted against each other and linear regression was used to fit the standard curve. The $\mathrm{IC}_{50}$ value was obtained from the linear regression.

\section{Anti-hyaluronidase activity}

Hyaluronidase inhibitory activity was measured by a modified method from the previous literature. ${ }^{[23]}$ Buffer A was prepared by mixing $82 \mathrm{mg}$ of $\mathrm{Na}_{2} \mathrm{HPO}_{4}, 51 \mathrm{mg}$ of $\mathrm{NaH}_{2} \mathrm{PO}_{4}, 0.225 \mathrm{NaCl}, 5 \mathrm{mg}$ of bovine serum albumin and dissolving in DI water to make a final volume at $50 \mathrm{~mL}$. Buffer B containing $63 \mathrm{mg}$ of $\mathrm{Na}_{2} \mathrm{HPO}_{4}$ and $1.76 \mathrm{~g}$ of $\mathrm{NaH}_{2} \mathrm{PO}_{4}$ in $50 \mathrm{~mL}$ of DI water was prepared. Bovine serum albumin solution was prepared by mixing $50 \mathrm{mg}$ of bovine serum albumin, $98.4 \mathrm{mg}$ of $\mathrm{CH}_{3} \mathrm{COONa}$, $237 \mathrm{mg}$ of $\mathrm{CH}_{3} \mathrm{COOH}$, and $40 \mathrm{~mL}$ of DI water. The $\mathrm{pH}$ value of the bovine serum albumin solution was adjusted to $\mathrm{pH} 3.75$ by adding hydrochloric acid solution and DI water was then added to adjust the final volume to $50 \mathrm{~mL}$. Aqueous extract was dissolved in DI water. Ethanolic extracts and oleanolic acid (positive control) were dissolved in methanol. Hyaluronidase enzyme solution $(15 \mathrm{U} / \mathrm{mL})$ was prepared in buffer A. Hyaluronic acid, which is a substrate, was dissolved in buffer $\mathrm{B}$ to make a solution at concentration of $0.03 \%$. The extract $(50 \mu \mathrm{L})$ in various concentrations was pipetted to a microtube to which $100 \mu \mathrm{L}$ of hyaluronidase enzyme solution was then added. After incubation at $37^{\circ} \mathrm{C}$ in a hot air oven for $10 \mathrm{~min}$, hyaluronic acid $(100 \mu \mathrm{L})$ was added and continually incubated at $37^{\circ} \mathrm{C}$ for $45 \mathrm{~min}$. The decomposition of hyaluronic acid was stopped by adding the bovine serum albumin solution $(1 \mathrm{~mL})$ to the mixture and placed in room temperature $\left(25-30^{\circ} \mathrm{C}\right)$ for $10 \mathrm{~min}$. The solution was pipetted to a 96-well plate and the absorbance measured of undigested hyaluronic acid at $600 \mathrm{~nm}$ using a UV-Vis microplate reader (Spectro StarNano, Germany). The percentage of enzyme inhibition was calculated from absorbance of sample reaction divided by absorbance of hyaluronic acid. $\mathrm{IC}_{50}$ value was obtained from the linear regression of \%inhibition against concentration.

\section{Anti-collagenase activity}

Collagenase activity measurements employed colorimetric assay kits using FALGPA as substrate in the enzymatic reaction. Aqueous extract and ethanolic extract solutions were prepared in water and ethanol, respectively. The mixture containing $5 \mu \mathrm{L}$ of the extract, $10 \mu \mathrm{L}$ of $0.35 \mathrm{U} / \mathrm{mL}$ collagenase enzyme, and $85 \mu \mathrm{L}$ of collagenase assay buffer in a UV transparent 96 -well plate was incubated in a hot air oven at $37^{\circ} \mathrm{C}$ for $10 \mathrm{~min}$. The reaction was started by adding $40 \mu \mathrm{L}$ of FALGPA and $60 \mu \mathrm{L}$ of collagenase assay buffer to the mixture. The absorbance at $345 \mathrm{~nm}$ was 
measured immediately after adding the substrate and then continuously for 15 min using a UV-microplate reader (Spectro StarNano, Germany) providing the linear regression of absorbance (Y-axis) and time (X-axis). The slope from the linear regression was used to calculate percentage of inhibition, as given below:

$$
\% \text { Inhibition }=[(\mathrm{A}-(\mathrm{B}-\mathrm{C})) \times 100] / \mathrm{A}
$$

Where A: slope obtaining from the linear regression of the mixture of collagenase enzyme, collagenase assay buffer, and FALGPA

B: slope obtaining from the linear regression of the mixture of sample solution, collagenase enzyme, collagenase assay buffer, and FALGPA

C: slope obtaining from the linear regression of the mixture of sample solution, collagenase assay buffer, and FALGPA

Then, $\mathrm{IC}_{50}$ was obtained from the linear regression between the percentage of inhibition and concentration.

\section{Antibacterial activity}

Measurement of antibacterial activity in this study was modified from the previous literature. ${ }^{[24]}$ S. aureus DMST 8013 and S. epidermidis DMST 15505 were purchased from Department of Medical Sciences, Thailand. Bacteria was grown in $\mathrm{MHB}$ at $37^{\circ} \mathrm{C}$ for $18-20 \mathrm{~h}$ and then diluted in normal saline solution to approximately $10^{6} \mathrm{cfu} / \mathrm{mL}$. The paper disc diffusion method was used to determine inhibition zone. Diluted bacterial suspension was spread on MHA and then a sterile paper disc $(6 \mathrm{~mm}$ diameter) was placed on the surface of MHA. Extracts were diluted in DMSO and then filtrated using a $0.45 \mu \mathrm{m}$ sterile membrane filter. The extracts were dropped $(20 \mu \mathrm{L})$ onto the paper disc at the final amount $2 \mathrm{mg} /$ disc. Clindamycin $(2 \mu \mathrm{g} / \mathrm{disc})$ was used as a reference antibiotic. Then, the plates were incubated at $37^{\circ} \mathrm{C}$ for $18 \mathrm{~h}$. All tests were performed in triplicate. The diameter of inhibition zones $(\mathrm{mm})$ was measured.

Microbroth dilution method was used to determine the minimum inhibitory concentration (MIC) and minimum bactericidal concentration (MBC). Overnight cultures of bacteria were diluted in MHB to approximately $10^{6} \mathrm{cfu} / \mathrm{mL}$ and then added $(100 \mu \mathrm{L})$ into a 96 -well plate. Extracts and gentamycin (a reference antibiotic) were diluted in MHB to various concentration and then added $(100 \mu \mathrm{L})$ into the bacterial suspension in the well plate. After incubation at $37^{\circ} \mathrm{C}$ for $24 \mathrm{~h}$, bacterial growth was observed from the media turbidity. MIC was determined as the lowest concentration that showed no bacterial growth in the wells. Then culture from concentrations at $\geq$ MIC were transferred $(20 \mu \mathrm{L})$ to soyabean casein digest agar. After incubation at $37^{\circ} \mathrm{C}$ for $24 \mathrm{~h}$, bacterial colonies were counted. MBC was determined as the lowest concentration that no bacterial colony. All tests were performed in triplicate.

\section{Formulation of T. erecta flower extract lotions}

In order to determine the stability and skin irritation of T. erecta flower extract in the formulation, $T$. erecta flower extract lotions were formulated. A beaker method was employed by using polysorbate 20 and sorbitan monooleate as the emulsifiers. Carbomer $934(0.4 \%)$ was dispersed in water and then gel was formed after adding triethanolamine (1.5\%). The water phase containing polysorbate $20(2.4 \%)$, polyethylene glycol $400(0.5 \%)$, carbomer 934 gel, and water (adjust to give 100\%) was heated up in water bath at $75-78^{\circ} \mathrm{C}$. The oil phase included sorbitan monooleate (3.5\%), glyceryl monostearate (2.0\%), petrolatum (2\%), and isopropyl myristate $(2.0 \%)$, was heated in water bath at $72-75^{\circ} \mathrm{C}$. Afterwards, the oil phase was added into the water phase and gently mixed. The extract (1\%) was dissolved in ethanol. After the lotion had cooled to $40-50^{\circ} \mathrm{C}$, the extract solution was added into the lotion and mixed until the smooth lotion was formed. The developed lotion was kept in glass bottle with tight cap. Lotion base containing the same ingredients and quantities, but no adding $T$. erecta flower extract was prepared as a control sample.

\section{Stability test}

Heating and cooling cycles were employed for stability testing of T. erecta lotions. The lotion in a glass bottle was stored at $4^{\circ} \mathrm{C}$ in a refrigerator for $12 \mathrm{~h}(n=3)$ followed by $12 \mathrm{~h}$ at $45^{\circ} \mathrm{C}$ with a total of 6 repeated cycles of heating and cooling. Physical appearance including texture, color, phase separation, precipitation, and odor, and $\mathrm{pH}$ value were evaluated prior and after heating and cooling cycles.

\section{Skin irritation test in healthy volunteers}

The protocol for the skin irritation test in healthy volunteers $(n=30)$ was reviewed and approved by the human research ethical committee, Faculty of Pharmacy, Mahasarakham University, Thailand (Approval No. 007/2560). Participants were entered according to specific inclusion criteria and excluded according to specific exclusion criteria. Inclusion criteria were healthy volunteers between 18 and 60 years of age. Volunteers were excluded if pregnant, breast feeding, in treatment with medicines, experiencing heart, liver, kidney, endocrine or immune systems diseases, experiencing skin allergies from the ingredients in T. erecta lotions, experiencing allergy to pollen, and participation into any clinical study. All participants gave written informed consent. Lotions $(0.5 \mathrm{~mL})$ were applied at inside of right upper arm for T. erecta lotion and left upper arm for lotion base and gently spread over an area of $1.5 \times 2 \mathrm{~cm}^{2}$. Afterward, the test sites were covered with gauze for $30 \mathrm{~min}$. Clinical assessments of the test sites were performed after removing the gauze consecutively at $24 \mathrm{~h}$ and $48 \mathrm{~h}$. Guideline from the International Contact Dermatitis Research Group was applied for evaluating skin irritation based on morphology (Table 1). The study was to be discontinued if the participant required or if the investigators deemed it necessary for medical reasons.

\section{Statistical analysis}

All results were presented as mean and standard deviation (SD). One-way ANOVA with least significant difference (LSD) post hoc test was employed using IBM SPSS Statistics 26. $P<0.05$ was considered as indicative of statistically significant difference.

\section{RESULTS}

\section{Total phenolic content in T. erecta flower extract}

The percent yields of extractions are shown in Table 2. The results showed that the highest percent yield was found in $50 \%$ ethanolic extract followed by aqueous extract and $95 \%$ ethanolic extract, respectively. For total phenolic content, the $95 \%$ ethanolic extract possessed the highest total phenolic content at $86.75 \pm 0.49 \mu \mathrm{g} \mathrm{GAE} / \mathrm{mg}$ extract at $p<0.05$ followed by $50 \%$ ethanolic extract and aqueous extract, respectively as shown in Table 2.

\section{Quantitative analysis of syringic acid in T. erecta flower extract}

Syringic acid was used as a chemical marker in the extracts and quantitatively analyzed by using HPLC. The chromatogram of syringic acid and the extracts are presented in Figure 1. The retention time of syringic acid was $31 \mathrm{~min}$. Syringic acid was able to be determined in three extracts. For quantitative analysis, the amount of syringic acid found in the three extracts is shown in Table 2. Among the extracts, $95 \%$ ethanolic extract contained the highest amount of syringic acid at $p<0.05$.

\section{Antioxidant activity}

Antioxidant assessment, DPPH assay revealed activity for all extracts and the inhibitory concentration $\left(\mathrm{IC}_{50}\right.$ ) of samples toward $\mathrm{DPPH}$ free 
Table 1: Scoring of skin reaction according to the International Contact Dermatitis Research Group recommendations.

\begin{tabular}{|c|c|c|}
\hline Symbol & Morphology & Interpretation \\
\hline- & No reaction & Negative \\
\hline$?$ & Erythema only, no infiltration & Doubtful reaction \\
\hline+ & $\begin{array}{l}\text { Erythema, infiltration, possibly discrete } \\
\text { papules }\end{array}$ & $\begin{array}{l}\text { Weak positive } \\
\text { reaction }\end{array}$ \\
\hline++ & Erythema, infiltration, papules, vesicles & $\begin{array}{l}\text { Strong positive } \\
\text { reaction }\end{array}$ \\
\hline+++ & Erythema, infiltration, confluent vesicles & $\begin{array}{l}\text { Extreme positive } \\
\text { reaction }\end{array}$ \\
\hline Ir & $\begin{array}{l}\text { Different types of reactions (soap effect, } \\
\text { vesicles, blister, necrosis) }\end{array}$ & Irritant reaction \\
\hline $\mathrm{Nt}$ & & Not tested \\
\hline
\end{tabular}

Table 2: Quantitative phytochemical analysis of $T$. erecta extracts.

\begin{tabular}{cccc}
\hline Extract & Yield (\%) & $\begin{array}{c}\text { Total phenolics } \\
(\mu \mathrm{g} \mathrm{GAE} / \mathrm{mg} \text { extract })\end{array}$ & $\begin{array}{c}\text { Syringic acid in } \\
\text { extract } \\
(\mathrm{mg} / \mathrm{g} \text { extract) }\end{array}$ \\
\hline Aqueous & $27.52 \%$ & $21.69 \pm 0.28$ & $2.331 \pm 0.033$ \\
$50 \%$ Ethanol & $37.41 \%$ & $54.11 \pm 1.01$ & $2.623 \pm 0.127$ \\
$95 \%$ Ethanol & $18.91 \%$ & $86.75 \pm 0.49^{*}$ & $3.343 \pm 0.119^{*}$ \\
\hline
\end{tabular}

${ }^{*}$ significant difference between extracts in each analysis $(p<0.05)$
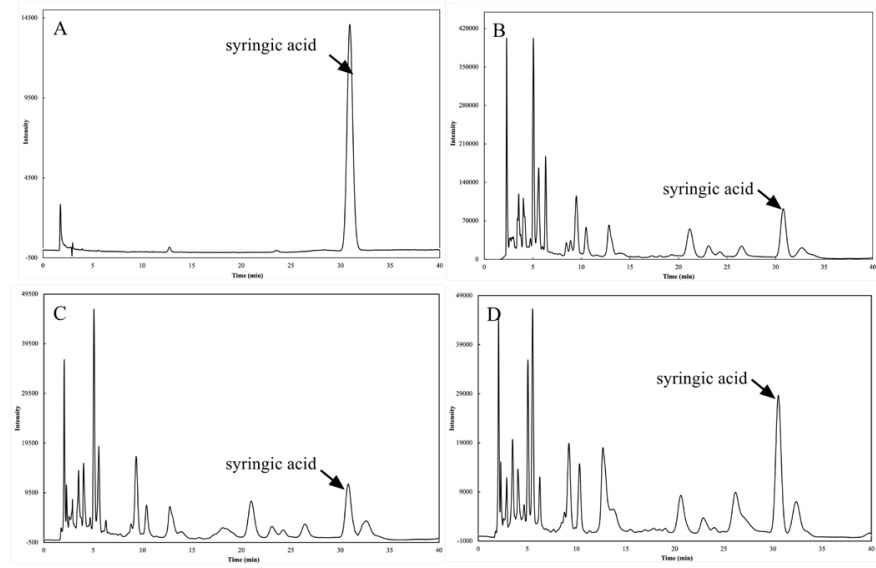

Figure 1: HPLC chromatograms (A: syringic acid, B: aqueous extract, C: $50 \%$ ethanolic extract, D: 95\% ethanolic extract)

radical scavenging activity are shown in Figure 2. The 95\% ethanolic extract showed the strongest radical scavenging activities compared with $50 \%$ ethanolic and aqueous extracts $(p<0.05)$. The $95 \%$ ethanolic extract was comparable to the positive control, ascorbic acid $(p>0.05)$.

\section{Biological activities of $T$. erecta extract}

\section{Anti-tyrosinase activity}

Inhibition of tyrosinase enzyme activity is shown in Figure 3. $\mathrm{IC}_{50}$ values of three extracts were significantly lower than that of the positive control, kojic acid. The lowest of $\mathrm{IC}_{50}$ value was possessed by the ethanolic extracts. The $95 \%$ ethanolic extract exhibited the best activity followed by $50 \%$ ethanolic and aqueous extract, respectively.

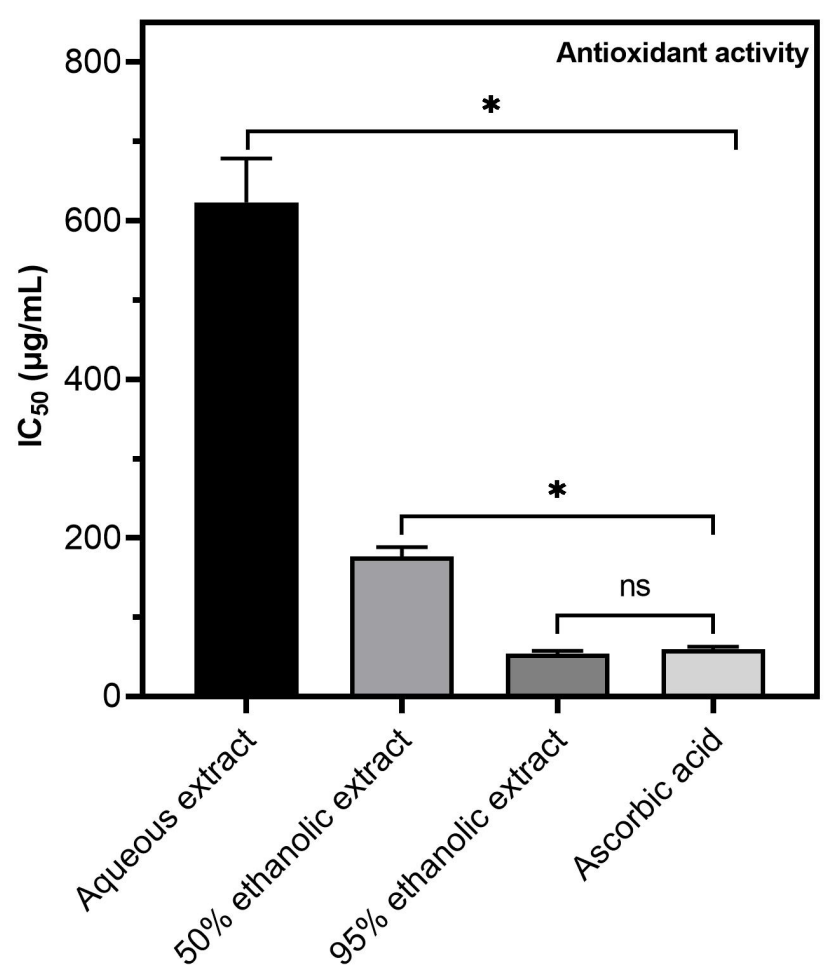

Figure 2: Antioxidant activity of T. erecta extracts.

*significant difference when compared with positive control $(p<0.05)$, ns: non-significant difference when compared with positive control

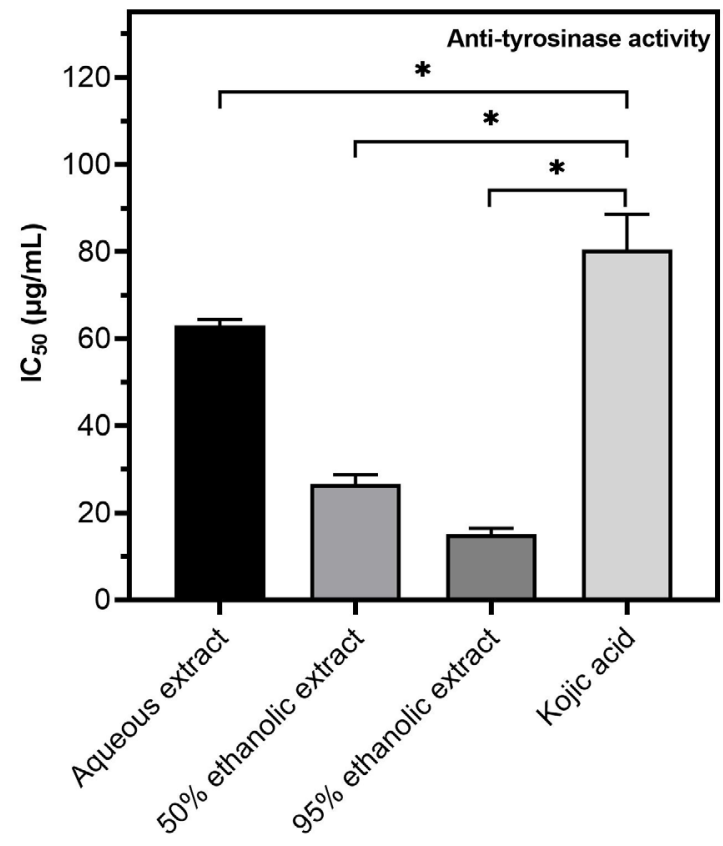

Figure 3: Anti-tyrosinase activity of T. erecta extracts.

*significant difference when compared with positive control $(p<0.05)$ 


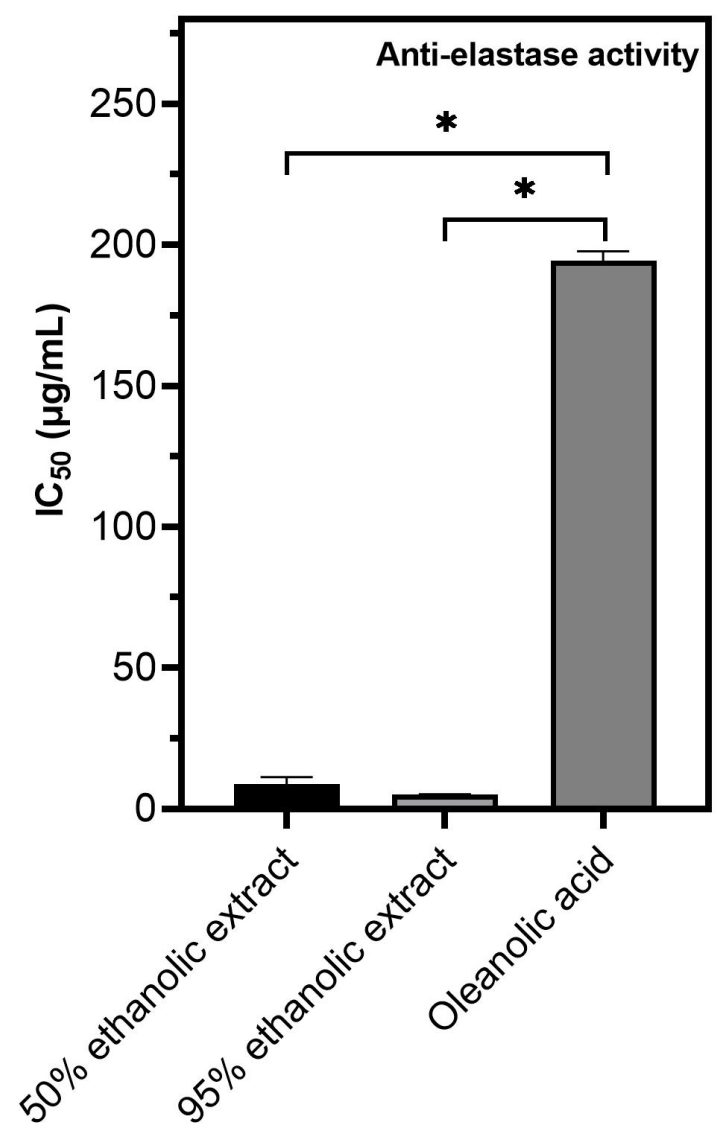

Figure 4: Anti-elastase activity of $T$. erecta extracts.

* significant difference when compared with positive control $(p<0.05)$

\section{Anti-elastase activity}

The ethanolic extracts exhibited anti-elastase activities that were more potent than that of oleanolic acid, a positive control $(p<0.05)$ (Figure 4$)$. Whereas the aqueous extract showed no anti-elastase activity even when the concentration was as high as $1 \mathrm{mg} / \mathrm{ml}$.

\section{Anti-hyaluronidase activity}

Assay of anti-hyaluronidase activity, was based on precipitation of hyaluronic acid which is used for high throughput screening for hyaluronidase inhibitors. ${ }^{[25]}$ Among three extracts, 95\% ethanolic extract showed the highest activity in hyaluronidase inhibition followed by $50 \%$ ethanolic extract and aqueous extracts, respectively. However, three extracts had weaker inhibitory effect than positive control, oleanolic acid $\left(\mathrm{IC}_{50}\right.$ of $\left.17.28 \pm 2.62 \mu \mathrm{g} / \mathrm{mL}\right)$ as shown in Figure 5 .

\section{Anti-collagenase activity}

Three extracts had activities against collagenase enzyme and were ranked in the order of $50 \%$ ethanolic extract $>95 \%$ ethanolic extract $>$ aqueous extract as illustrated in Figure 6. The efficacy against collagenase enzyme of the $50 \%$ ethanolic extract was comparable to the positive control. However, the $\mathrm{IC}_{50}$ values of the aqueous and $95 \%$ ethanolic extracts were higher than that of positive control, epigallocatechin gallate $(p<0.05)$.

\section{Antibacterial activity}

From Table 3, 95\% and 50\% ethanolic extracts showed antibacterial activity against $S$. aureus and $S$. epidermidis whereas aqueous extract did not inhibit bacterial growth. The $95 \%$ ethanolic extract inhibited bacterial growth more than the $50 \%$ ethanolic extract. In addition, $95 \%$ ethanolic

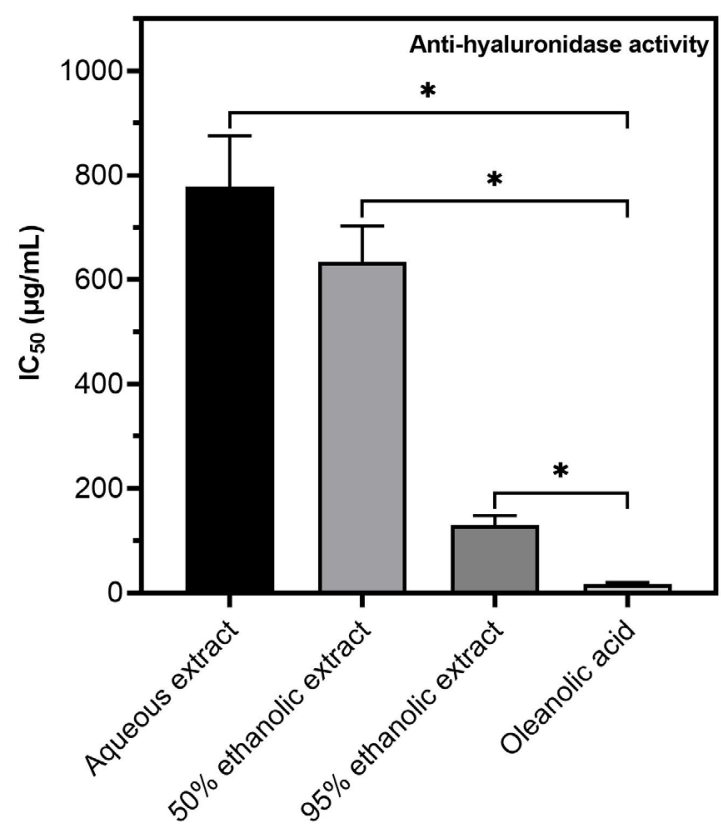

Figure 5: Anti-hyaluronidase activity of T. erecta extracts. *significant difference when compared with positive control $(p<0.05)$

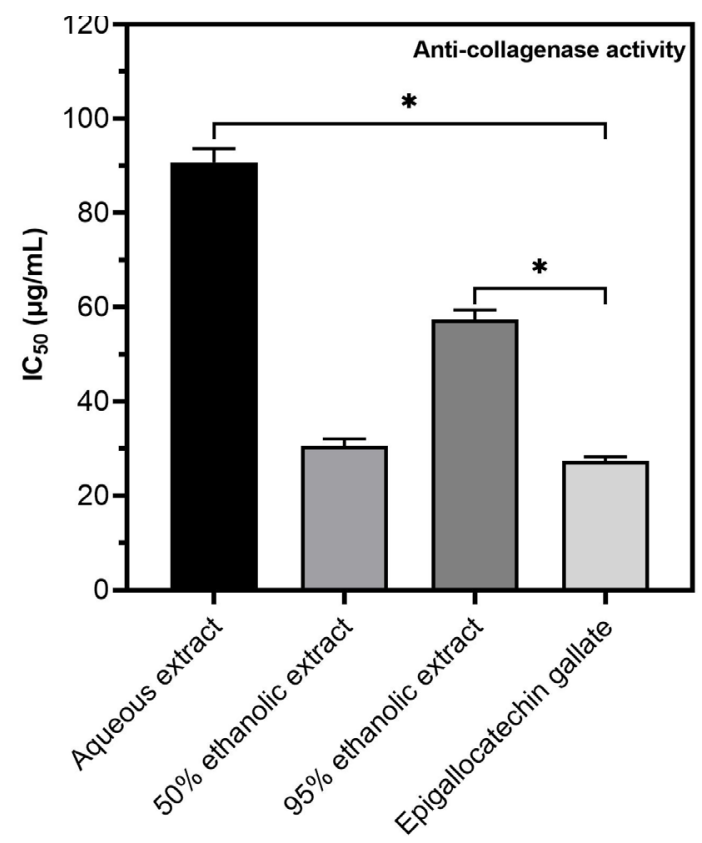

Figure 6: Anti-collagenase activity of T. erecta extracts. ${ }^{*}$ significant difference when compared with positive control $(p<0.05)$

extract had greater bactericidal activity against $S$. epidermidis than S. aureus.

\section{Stability of T. erecta lotions}

According to the results of the biological activity studies, T. erecta flower that was extracted using $95 \%$ ethanol showed a greater potential to develop as a cosmeceutical product. Therefore, T. erecta lotions using $95 \%$ ethanolic extract was developed as a prototype product in order to examine the stability of the extract. T. erecta lotion after being freshly 
Table 3: Antibacterial activity of $T$. erecta extracts.

\begin{tabular}{|c|c|c|c|c|c|c|}
\hline \multirow{2}{*}{$\begin{array}{l}\text { Extracts/ } \\
\text { antibiotics }\end{array}$} & \multicolumn{3}{|c|}{ S. aureus } & \multicolumn{3}{|c|}{ S. epidermidis } \\
\hline & 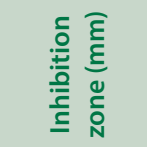 & $\begin{array}{l}\text { ठे } \\
\underline{\underline{\varepsilon}} \vec{\xi} \\
\Sigma\end{array}$ & $\begin{array}{l}\text { छे } \\
\text { छે } \\
\sum_{\Sigma}^{\infty}\end{array}$ & 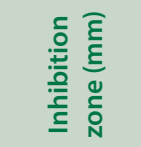 & $\begin{array}{l}\text { ठे } \\
\underline{\underline{\varepsilon}} \vec{\xi} \\
\Sigma\end{array}$ & 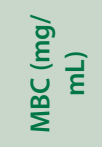 \\
\hline Aqueous & $\mathrm{ni}$ & nd & nd & $\mathrm{ni}$ & nd & nd \\
\hline 50\% Ethanol & $9.67 \pm 1.53$ & $>8$ & $>8$ & $10.00 \pm 2.00$ & 8 & $>8$ \\
\hline 95\% Ethanol & $15.00 \pm 1.00$ & 4 & 8 & $16.00 \pm 0.00$ & 4 & 4 \\
\hline Clindamycin & $29.67 \pm 0.58$ & nd & nd & $32.33 \pm 0.58$ & nd & nd \\
\hline Gentamycin & nd & 0.00097 & 0.00097 & nd & 0.00097 & 0.00097 \\
\hline
\end{tabular}

ni is no inhibition zone, nd is no determination

Table 4: Skin reaction of the test sites after applied $T$. erecta lotions.

\begin{tabular}{ccc}
\hline \multirow{2}{*}{$\begin{array}{c}\text { Assessment } \\
\text { time }(\mathrm{h})\end{array}$} & \multicolumn{2}{c}{ Skin reaction } \\
\cline { 2 - 3 } & T. erecta lotions & Lotion base \\
\hline 0.5 & - (no reaction) & - (no reaction) \\
24 & - (no reaction) & - (no reaction) \\
48 & - (no reaction) & - (no reaction) \\
\hline
\end{tabular}

prepared, was light-yellow, had smooth texture and was easily applied onto the skin. After passing through heating and cooling cycles, its texture, odor, and color were stable. There was no phase separation or solid precipitation. The $\mathrm{pH}$ values of $T$. erecta lotion containing $1 \%$ of the $95 \%$ ethanolic extract were stable at $\mathrm{pH} 6.15 \pm 0.03$.

\section{Skin irritation of T. erecta lotions in healthy volunteers}

A total of 30 healthy volunteers (11 men and 19 women, aged $22.50 \pm 1.12$ years) were recruited from the Mahasarakham University (Thailand) and the surrounding area. The volunteers were received verbal and written information and gave their informed consent. All participants completed the study without protocol deviation. After application of the developed lotion containing $1 \%$ of $95 \%$ ethanolic extract or lotion base there were no signs or symptoms of skin irritation in 30 healthy volunteers immediately or after $30 \mathrm{~min}, 24 \mathrm{~h}$, and $48 \mathrm{~h}$ (Table 4 ).

\section{DISCUSSION}

T. erecta flowers not only contribute to ceremonial or decorative purposes but have also been reported to be utilized as an herbal medicine. Antielastase, anti-hyaluronidase, and anti-collagenase properties of T. erecta have been established in previous studies. However, the previous studies investigated the efficacy in T. erecta flower extracted by methanol, butanol, and ethyl acetate, in which residual methanol, butanol, and ethyl acetate may remain in the extracts causing possible toxicity. ${ }^{[18,19]}$ Moreover, there have been no comprehensive studies reporting the biological effects on the skin including antiaging properties throughout inhibitory properties on oxidation reaction and antibacterial activity, along with human skin irritation testing of T. erecta flower extract. Therefore, this study focused on the simultaneous biological effects on the skin and skin irritation studies of $T$. erecta flower extracts by using biocompatible and low toxicity solvents. Thereby, water, $95 \%$ ethanol and 50\% ethanol were selected for the plant extraction. Syringic acid, a phenolic compound, was selected as a chemical marker in this study due to it having been reported to have been antiaging activity in previous studies. ${ }^{[3]}$ However, the quantity of syringic acid in T. erecta flower extracts has not been reported. Considering the biological activity of syringic acid, it has been found in various plants and possesses antioxidant activity, ${ }^{[26-28]}$ cyclooxygenase-2 inhibitory, ${ }^{[28]}$ and anticancer effects. ${ }^{[29]}$ In the current study, syringic acid was found to be higher in the $95 \%$ ethanolic extract compared with the other extracts. The highest phenolic content was also found in $95 \%$ ethanolic extract. These results demonstrated the correlation between ethanol concentration for extraction and syringic acid content and total phenolic contents. A higher ethanol concentration in the extraction process, higher syringic acid and total phenolic contents were obtained. Moreover, the three $T$. erecta flower extracts in the present study had higher amount of total phenolic contents compared to $95 \%$ ethanolic, $50 \%$ ethanolic and aqueous extract of $T$. erecta flower extracts in the previous study $(48.27 \pm 0.26,46.36 \pm 0.26$, and $8.50 \pm 0.10 \mu \mathrm{g}$ $\mathrm{GAE} / \mathrm{mg}$ extract, respectively). ${ }^{[1]}$ Considering the process of extraction, in the previous study, the extracts were obtained by maceration at $30^{\circ} \mathrm{C}$ for $24 \mathrm{~h}^{[1]}$ while in this study, aqueous extract was obtained by soaking at $70-80^{\circ} \mathrm{C}$ for $1 \mathrm{~h}$ and ethanolic extracts were prepared by maceration at room temperature $\left(25-30^{\circ} \mathrm{C}\right)$ for 5 days. These findings showed that temperature in the case of aqueous extract and duration of maceration in the case of ethanolic extracts played crucial roles in determining the phenolic and syringic acid content.

For investigation of antioxidant activity, the method was based on a single relatively stable reagent, DPPH which is the most popular method because of it is controllable and simple to set-up becoming a routine tool for the rapid identification of antioxidants in plant extracts. ${ }^{[30]}$ The results in this study revealed a high correlation between antioxidant activities and total phenolic content as well as syringic acid contents. Increasing ethanol concentration for the plant extraction increased total phenolic content, syringic acid concentration, and antioxidant activity. The highest total phenolic content possessed the highest antioxidant activity. From many antioxidative studies, phenolic compounds have been proven to be the best free radical scavengers and inhibition of lipid peroxidation. ${ }^{[31]}$ Previously, the antioxidant capacity of $T$. erecta flower extracts had been reported to markedly contribute from the amount of phenolic compounds in the extracts. ${ }^{[32]}$ Thereby, the phenolic compounds in T. erecta flower may play a crucial rule in its antioxidant activity.

Several studies have been investigated potential activities of phenolic compounds on skin aging. The phenolic compounds have been proposed for aging prevention and contributed to treatment of skin aging problems. ${ }^{[33]}$ Possible aging prevention or anti-aging properties of $T$. erecta flower, which is rich of phenolic compounds, has been considered. Aforementioned, skin aging is caused by the increased production of reactive oxygen species, elastase, hyaluronidase, collagenase, and tyrosinase activities leading to loss of skin strength, loss of skin elasticity, skin dryness, wrinkles and sagging formation. Approaches that inhibit these enzymes activities, can be applied as useful methods to protect skin aging. This study revealed an anti-aging property of T. erecta flower via inhibition these enzymes activities. The 95\% ethanolic extracts of T. erecta flower showed the greatest potential to be an anti-aging agent. In comparison to previous studies, the $95 \%$ ethanolic extract in this study $\left(\mathrm{IC}_{50}\right.$ of $5.05 \pm 1.41 \mu \mathrm{g} / \mathrm{mL}$ ) showed anti-elastase effects similar to the methanol and butanol extracts of $T$. erecta flower in the previous study $\left(\mathrm{IC}_{50}\right.$ of $4.13 \pm 0.93$ and $4.01 \pm 1.37 \mu \mathrm{g} / \mathrm{mL}$, respectively) ${ }^{[3]}$ A recent study demonstrated that the ethanolic $T$. erecta flower extracts had the greater anti-elastase and anti-tyrosinase activities compared with ethyl acetate T. erecta flower extracts in the previous study. The ethyl acetate T. erecta flower extracts at concentration of $125 \mu \mathrm{g} / \mathrm{mL}$ showed \% inhibition at $5.5 \%$ for inhibitory activity against elastase enzyme and showed $\mathrm{IC}_{50}$ value for anti-tyrosinase activity at $1,467 \mu \mathrm{g} / \mathrm{mL} .^{[11]}$ However, the aqueous extract in the current study at a concentration more than $1 \mathrm{mg} / \mathrm{mL}$ showed \% inhibition less than $50 \%$ in the anti-elastase study. Therefore, $\mathrm{IC}_{50}$ values of aqueous extract cannot be determined. These findings 
indicate that the different solvents for plant extraction may demonstrate the different biological activities. Additionally, the use of ethanol instead of other highly toxic organic solvents in the extraction of T. erecta flower demonstrates the greater anti-aging effects.

Antibacterial activities of T. erecta flower extracts against two particular bacteria associated with acne, S. epidermidis and S. aureus, were also determined. Extracts (particularly 95\% ethanolic extract), showed antibacterial activity correlated with the previous studies. Jain et al. reported that $T$. erecta extracts exhibited antibacterial activity against both gram negative and gram positive cells including Escherichia coli, Proteus vulgaris, P. mirabilis, Aeromonas sobria, A. hydrophila, Plesiomonas shigelloides, Salmonella enterica serotype Typhi, S. enterica serotype Typhimurium, S. enterica serotype Aboni, S. enterica serotype Enteritidis, Bacillus subtilis, B. cereus, B. circulans, and S. aureus. ${ }^{[34]}$ The ethanolic extract from $T$. erecta showed antibacterial activity against $B$. cereus, S. aureus, S. epidermidis, S. typhi, Klebsiella pneumoniae, E. coli, P. aeruginosa and P. mirabilis. ${ }^{[35]}$ A mode of action in which the extract caused deformation and lysis of $S$. aureus cells was also reported. ${ }^{[35]}$ These results indicated the potential effect of T. erecta especially $95 \%$ ethanolic extract on bacterial growth inhibition. There is report showing that aged skin is found to be a susceptible skin infection. In neonates, adipose tissue in adipocyte promotes innate immunity via production of antimicrobial peptide (cathelicidin). Ages skin is found the thinning of skin adipose tissue resulting in decrease of cathelicidin followed by impairment of $S$. aureus clearance and loss of antimicrobial function. ${ }^{[36]}$ Therefore, antibacterial activities of $T$. erecta flower extracts may be useful for aged skin. According to the results of antioxidant activity and the biological activities of $T$. erecta flower extracts, $95 \%$ ethanolic extract which contained higher amounts of total phenolic and syringic acid and possessed stronger radical scavenging activities, inhibitory effects against skin aging-related enzymes and against bacterial growth, had a potential to be a natural source of bioactive compounds for development of cosmeceutical skin products. Therefore, 95\% ethanolic extract was selected to formulate as a prototype product in order to study the stability of the extract when it is in the formulation as well as skin irritation after application on human skin. The content of $95 \%$ ethanolic extract at $1 \%$ was preliminarily selected for adding to this prototype product. The results from stability studies revealed that this formulation was stable. In addition, the formulation showed no skin irritation in healthy volunteers after it was applied for $48 \mathrm{~h}$. This study is the first study showing both the biological activities on the skin and the skin safety of T. erecta flower extracts. The results suggest potential of $T$. erecta flower extracts to be a source of bioactive compounds from a natural source for developing as a skin care product.

\section{CONCLUSION}

This study revealed that among three T. erecta flower extracts, ethanolic extract using 95\% ethanol was found to contain higher phenolic compounds and syringic acid than the others. It also had greater biological effects on the skin including antioxidant, anti-skin aging-related enzymes and antibacterial activity than the other extracts. Additionally, the lotion containing the ethanolic $T$. erecta flower extracts was physicochemical stable and was also safe for human skin. These findings highlight the potential of $T$. erecta flower extracted by $95 \%$ ethanol to be utilized in the skin care products as a natural source of phytochemical which it offers excellent biological activities and safe.

\section{ACKNOWLEDGEMENT}

This research was financially supported by Faculty of Pharmacy, Mahasarakham University, Maha Sarakham province, Thailand. We would like to thank Dr. Adrian Roderick Plant for his assistance proofreading this article.

\section{Author Contributions}

CM: conceptualization, methodology, writing - original draft. SM: methodology, writing - review and editing. NF: methodology, writing review and editing. WK and NS: methodology.

\section{CONFLICT OF INTEREST}

The authors declare no conflict of interest.

\section{ABBREVIATIONS}

SANA: N-succinyl-(Ala)-3-nitroaniline; FALGPA: N-[3-(2-furyl) acryIoyl]-Leu-Gly-Pro-Ala; L-DOPA: 3',4'-dihydroxy-l-phenylalanine

DPPH: 2,2-diphenyl-1-picrylhydrazy; MHB: Mueller Hinton broth, MHA: Mueller Hinton agar; IC $_{50}$ : half maximal inhibitory concentration or $50 \%$ inhibitory concentration; MIC: minimum inhibitory concentration; MBC: minimum bactericidal concentration.

\section{REFERENCES}

1. Gong Y, Liu $X, H e W H, X u H G$, Yuan $F, G a o Y X$. Investigation into the antioxidant activity and chemical composition of alcoholic extracts from defatted marigold (Tagetes erecta L.) residue. Fitoterapia. 2012;83(3):481-9. doi: 10.1016/j.fitote. 2011.12.013, PMID 22223143.

2. Faizi S, Naz A. Palmitoleate (=(9Z)-Hexadeca-9-enoate) esters of oleanane triterpenoids from the golden flowers of Tagetes erecta: isolation and autoxidation products. Helv Chim Acta. 2004;87(1):46-56. doi: 10.1002/hlca.200490016.

3. Maity N, Nema NK, Abedy MK, Sarkar BK, Mukherjee PK. Exploring Tagetes erecta Linn flower for the elastase, hyaluronidase and MMP-1 inhibitory activity. J Ethnopharmacol. 2011:137(3):1300-5. doi: 10.1016/j.jep.2011.07.064, PMID 21843618.

4. Chopra R, Nayar S, Chopra I. Glossary of Indian medicinal plants. New Delhi, India: council of scientific and industrial research; 1956.

5. Neher RT. The ethnobotany of tagetes. Econ Bot. 1968;22(4):317-25. doi: 10.1007/BF02908126.

6. Bashir S, Gilani AH. Studies on the antioxidant and analgesic activities of Aztec marigold (Tagetes erecta) flowers. Phytother Res. 2008:22(12):1692-4. doi: 10.1002/ptr.2550, PMID 18814202.

7. Kazibwe Z, Kim DH, Chun S, Gopal J. Ultrasonication assisted ultrafast extraction of Tagetes erecta in water: cannonading antimicrobial, antioxidant components. J Mol Liq. 2017;229:453-8. doi: 10.1016/j.molliq.2016.12.044

8. Meurer MC, Mees M, Mariano LNB, Boeing T, Somensi LB, Mariott M, da Silva RCMVAF, Dos Santos AC, Longo B, Santos FrançaTC, Klein-Júnior LC, de Souza P, de Andrade SF, da Silva LM. Hydroalcoholic extract of Tagetes erecta L. flowers, rich in the carotenoid lutein, attenuates inflammatory cytokine secretion and improves the oxidative stress in an animal model of ulcerative colitis. Nutr Res. 2019;66:95-106. doi: 10.1016/j.nutres.2019.03.005, PMID 30979660.

9. Pérez-Ortega G, Angeles-López GE, Argueta-Villamar A, González-Trujano ME. Preclinical evidence of the anxiolytic and sedative-like activities of Tagetes erecta L. reinforces its ethnobotanical approach. Biomed Pharmacother 2017:93:383-90. doi: 10.1016/j.biopha.2017.06.064, PMID 28654794.

10. Phrutivorapongkul A, Kiattisin K, Jantrawut $P$, Chansakaow S, Vejabhikul S, Leelapornpisid P. Appraisal of biological activities and identification of phenolic compound of African marigold (Tagetes erecta) flower extract. Pak J Pharm Sci. 2013;26(6):1071-6. PMID 24191339.

11. Vallisuta $O$, Nukoolkarn $V$ Mitrevej A Sarisuta $N$ Leelapornpisid $P$ Phrutivorapongkul A, Sinchaipanid N. In vitro studies on the cytotoxicity, and elastase and tyrosinase inhibitory activities of marigold (Tagetes erecta L.) flower extracts. Exp Ther Med. 2014;7(1):246-50. doi: 10.3892/etm.2013.1373, PMID 24348799

12. Leelapornpisid P, Chansakaow S, Na-Boonlong S, Jantrawut P. Development of cream containing nanostructured lipid carriers loaded marigold (Tagetes erecta Linn) flowers extract for anti-wrinkles application. Int J Pharm Pharm Sci. 2014;6(5):309-13

13. Jenkins G. Molecular mechanisms of skin ageing. Mech Ageing Dev. 2002;123(7):801-10. doi: 10.1016/s0047-6374(01)00425-0, PMID 11869737.

14. Bose B, Choudhury H, Tandon P, Kumaria S. Studies on secondary metabolite profiling, anti-inflammatory potential, in vitro photoprotective and skin-aging related enzyme inhibitory activities of Malaxis acuminata, a threatened orchid of nutraceutical importance. J Photochem Photobiol B. 2017:173:686-95. doi: 10.1016/j.jphotobiol.2017.07.010, PMID 28743100.

15. Otto M. Staphylococcus epidermidis - the "accidental" pathogen. Nat Rev Microbiol. 2009;7(8):555-67. doi: 10.1038/nrmicro2182, PMID 19609257.

16. Adler $\mathrm{BL}$, Kornmehl $\mathrm{H}$, Armstrong AW. Antibiotic resistance in acne treatment JAMA Dermatol. 2017:153(8):810-1. doi: 10.1001/jamadermatol.2017.1297, PMID 28636689. 
17. Gull A, Ahmed S, Ahmad FJ, Nagaich U, Chandra A. Effect of polyherbal microemulsion on Staphylococcus epidermidis: formulation development, CCD based optimization, characterization, and antibacterial activity by scanning electron microscopy. J Drug Deliv Sci Technol. 2020;57. doi: 10.1016/j. jddst.2020.101641, PMID 101641.

18. Moon CS. Estimations of the lethal and exposure doses for representative methanol symptoms in humans. Ann Occup Environ Med. 2017 Oct 2;29:44. doi: 10.1186/s40557-017-0197-5, PMID 29026612.

19. 5 Final report on the safety assessment of ethyl acetate and butyl acetate. J Am Coll Toxicol. 1989;8(4):681-705. doi: 10.3109/10915818909010527.

20. Pekal A, Pyrzynska K. Evaluation of aluminium complexation reaction for flavonoid content assay. Food Anal Methods. 2014;7(9):1776-82. doi: 10.1007/ s12161-014-9814-X.

21. Duvivier P, Hsieh P-C, Lai P-Y, Charles AL. Evaluation of drying methods on antioxidant activity, total phenolic and total carotenoid contents of sweet potato (/pomoea batatas L.) Lam.) var. Tainong 73. J Int Coop. 2008;3(2):73-86.

22. Zhang $C$, LuY, Tao L, Tao X, Su X, Wei D. Tyrosinase inhibitory effects and inhibition mechanisms of nobiletin and hesperidin from citrus peel crude extracts. J Enzyme Inhib Med Chem. 2007;22(1):91-8. doi: 10.1080/14756360600988989, PMID 17373553.

23. Chompoo J, Upadhyay A, Fukuta M, Tawata S. Effect of Alpinia zerumbet components on antioxidant and skin diseases-related enzymes. BMC Complement Altern Med. 2012;12(1):106. doi: 10.1186/1472-6882-12-106, PMID 22827920.

24. Chuangchot C, Tattawasart U, Sripanidkulchai B, Junlatat J, Fangkrathok N. Antibacterial and antioxidant activity of Rafflesia kerrii extract against multidrugresistant bacteria. Songklanakarin J Sci Technol. 2017;39(2):163-70.

25. Tung JS, Mark GE, Hollis GF. A microplate assay for hyaluronidase and hyaluronidase inhibitors. Anal Biochem. 1994;223(1):149-52. doi: 10.1006/ abio.1994.1560, PMID 7695091.

26. Hirota A, Taki S, Kawaii S, Yano M, Abe N. 1,1-diphenyl-2-picrylhydrazyl radicalscavenging compounds from soybean miso and antiproliferative activity of isoflavones from soybean miso toward the cancer cell lines. Biosci Biotechnol
Biochem. 2000;64(5):1038-40. doi: 10.1271/bbb.64.1038, PMID 10879475.

27. Schmeda-Hirschmann G, Tapia A, Theoduloz C, Rodríguez J, López S, Feresin GE. Free radical scavengers and antioxidants from Tagetes mendocina. Z Naturforsch C J Biosci. 2004;59(5-6):345-53. doi: 10.1515/znc-2004-5-610, PMID 18998399.

28. Stanikunaite R, Khan SI, Trappe JM, Ross SA. Cyclooxygenase-2 inhibitory and antioxidant compounds from the truffle Elaphomyces granulatus. Phytother Res. 2009;23(4):575-8. doi: 10.1002/ptr.2698, PMID 19067382

29. Dedoussis GVZ, Kaliora AC, Andrikopoulos NK. Effect of phenols on natural killer (NK) cell-mediated death in the K562 human leukemic cell line. Cell Biol Int. 2005:29(11):884-9. doi: 10.1016/j.cellbi.2005.07.006, PMID 16198604.

30. Niederländer HAG, van Beek TA, Bartasiute A, Koleva II. Antioxidant activity assays on-line with liquid chromatography. J Chromatogr A. 2008;1210(2):121-34. doi: 10.1016/j.chroma.2008.09.061, PMID 18849036

31. Atmani D, Chaher N, Berboucha M, Ayouni K, Lounis H, Boudaoud $H$, Debbache N. Atmani D. Antioxidant capacity and phenol content of selected Algerian medicinal plants. Food Chem. 2009;112(2):303-9. doi: 10.1016/j.foodchem.2008.05.077.

32. Kaisoon O, Konczak I, Siriamornpun S. Potential health enhancing properties of edible flowers from Thailand. Food Res Int. 2012;46(2):563-71. doi: 10.1016/j. foodres.2011.06.016

33. Thring TSA, Hili P, Naughton DP. Anti-collagenase, anti-elastase and antioxidant activities of extracts from 21 plants. BMC Complement Altern Med. 2009:9(27):27. doi: 10.1186/1472-6882-9-27, PMID 19653897.

34. Jain R, Katare N, Kumar V, Samanta A, Goswami S, Shrotri C. In vitro antibacterial potential of different extracts of Tagetes erecta and Tagetes patula. J Nat Sci Res. 2012;2(5):84-90.

35. Motamedi H, Seyyednejad SM, Bakhtiari A, Vafaei M. Tagetes erecta, a potential medicinal plant for discovering a new antibacterial agent. Jentashapir J Hea Res. 2015;6(4):e29744. doi: 10.17795/jjhr-29744.

36. Kobayashi T, Nagao K. 'Deepening' insight on skin aging and anti-microbial immunity. Cell Metab. 2019;29(3):515-7. doi: 10.1016/j.cmet.2019.02.006, PMID 30840910.

\section{GRAPHICAL ABSTRACT}

\section{Tagetes erecta L. flower extracts}

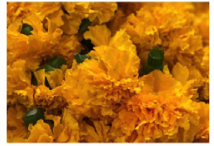

- Aqueous extract

- $50 \%$ ethanolic extract

$-95 \%$ ethanolic extract

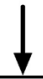

$95 \%$ ethanolic extract

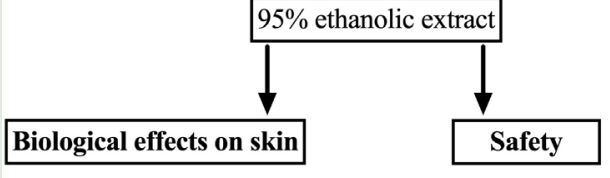

$\checkmark$ antioxidant

$\checkmark$ anti-skin aging-related enzymes

$\checkmark$ no skin irritation in healthy

volunteers

\section{SUMMARY}

This study focused on the simultaneous efficacy including antiaging properties throughout inhibitory properties on oxidation reaction and antibacterial activity, along with human skin irritation testing of the Tagetes erecta L. flower extract by using safe solvents, ethanol and water, for extraction. The results revealed that ethanolic extract using $95 \%$ ethanol was found to contain higher phenolic compounds and syringic acid than the others and had greater inhibitory effects on antioxidant, skin aging-related enzymes and antibacterial activity. The prototype formulation containing $1 \% T$. erecta ethanolic extract was physically stable and non-irritation to the skin in healthy volunteers.

$\checkmark$ antibacterial

$$
\begin{array}{|l|}
\hline \text { Potential source of bioactive compounds for } \\
\text { development of cosmeceutical skin products }
\end{array}
$$

Cite this article: Mekjaruskul C, Kumkarnjana S, Fangkrathok N, Kengkittipat W, Sirichat N. Potential Cosmeceutical Applications and Evaluation of Human Skin Irritation of Tagetes erecta L. Flower Extract. Pharmacog Res. 2021;13(4):199-207. 